\title{
Associated tears of the lateral meniscus in anterior cruciate ligament injuries: risk factors for different tear patterns
}

\author{
Matthias J Feucht, Sebastian Bigdon, Gerrit Bode, Gian M Salzmann, David Dovi-Akue, Norbert P Südkamp
} and Philipp Niemeyer

\begin{abstract}
Background: The pattern of lateral meniscus tears observed in anterior cruciate ligament (ACL)-injured subjects varies greatly and determines subsequent management. Certain tear patterns with major biomechanical consequences should be repaired in a timely manner. Knowledge about risk factors for such tears may help to identify patients in the early posttraumatic phase and subsequently may improve clinical results.

Methods: A database of 268 patients undergoing primary ACL reconstruction was used to identify all patients with isolated $A C L$ tears and patients with an associated tear of the lateral meniscus. Patients who underwent surgery $>6$ months after the injury were excluded. Based on the arthroscopic appearance of the lateral meniscus, patients were assorted to one of three groups: 'no tear,' 'minor tear,' and 'major tear.' Tear patterns defined as major included root tears, complete radial tears, and unstable longitudinal tears including bucket-handle tears. Univariate analysis was performed by comparing the three groups with regard to gender, age, height, weight, BMl, type of injury (high-impact sport, low-impact sport, and not sports related), and mechanism of injury (non-contact vs. contact). Multivariate logistic regression was carried out to identify independent risk factors for minor and major meniscal tears and to calculate odds ratios (OR).

Results: Two hundred fifteen patients met the inclusion and exclusion criteria. Of those, 56\% had isolated ACL tears, $27 \%$ had associated minor tears, and $17 \%$ had associated major tears of the lateral meniscus. Univariate analysis revealed significant differences between the three groups for gender $(p=0.002)$, age groups $(p=0.026)$, and mechanism of injury $(p<0.001)$. A contact injury mechanism was a risk factor for minor tears (OR: 4.28$)$ and major tears (OR: 18.49). Additional risk factors for major tears were male gender (OR: 7.38) and age <30 years (OR: 5.85).

Conclusion: Male patients, patients $<30$ years, and particularly patients who sustained a contact injury have a high risk for an associated major lateral meniscus tear. Special attention is therefore necessary in those patients and early referral to magnetic resonance imaging and/or arthroscopy is recommended to allow meniscus repair in a timely manner.
\end{abstract}

Keywords: Anterior cruciate ligament, ACL, Meniscus, Root tear, Contact injury

\footnotetext{
*Correspondence: matthias.feucht@gmx.net

Department of Orthopedic Surgery and Traumatology, Freiburg University Hospital, Albert Ludwigs University of Freiburg, Hugstetter Straße 55, 79106 Freiburg, Germany
} 


\section{Background}

Meniscus tears are commonly observed in patients with anterior cruciate ligament (ACL) injuries, with a reported prevalence of approximately $55 \%$ to $65 \%$ [1-6]. Several studies have shown that associated meniscal tears are strong predictors for the development and progression of knee osteoarthritis (OA) as well as worse patient reported outcomes after ACL reconstruction, especially if a partial or total meniscectomy is performed [7-11]. This observation has led to efforts to preserve as much meniscal tissue as possible, and meniscus repair combined with ACL reconstruction is increasingly preferred over meniscectomy [12,13].

Whereas medial meniscus tears are more common in patients with chronic ACL insufficiency, lateral meniscus tears are predominately found in acute ACL injuries $[14,15]$. Since the complexity of meniscus tears increase in the chronic stage, and tears are less amenable to repair as time passes [16,17], particularly lateral meniscus tears identified in the early posttraumatic phase may be best suitable for repair. The importance of lateral meniscus repair is emphasized by the fact that lateral meniscectomy is associated with a higher risk for osteoarthritis compared to medial meniscectomy [7,9].

The pattern of lateral meniscus tears observed in ACL-injured subjects varies greatly and determines subsequent management. Certain tear patterns, such as incomplete longitudinal tears or complete stable longitudinal tears have only minor consequences on knee joint health and can be left in situ [18-20]. In contrast, other tear patterns, such as root tears, complete radial tears, and bucket-handle tears, are associated with major biomechanical consequences and should be repaired in a timely manner to prevent rapid joint degeneration [21-24].

Different tear patterns of the lateral meniscus in ACLinjured subjects may be associated with different demographic and historical risk factors such as gender, age, body weight, and injury mechanism. Knowledge about such risk factors may help physicians to identify patients with major meniscal tears in the early posttraumatic phase. However, no study so far has analyzed risk factors for different tear patterns of the lateral meniscus in acute and subacute ACL-injured subjects. The purpose of this study was therefore to refine current knowledge about risk factor for associated meniscus tears in ACLinjured subjects by specifically analyzing risk factors for different tear patterns of the lateral meniscus.

\section{Methods}

\section{Study design}

A retrospective cohort design was used to examine the association between different tear patterns of the lateral meniscus in acute and subacute ACL-injured subjects and potential demographic and historical risk factors.
The study protocol was approved by the institutional review board of the University of Freiburg (Project No.: $170 / 14$ ), and the study was performed in accordance with the Declaration of Helsinki. Informed consent of the patients was not necessary since all data were obtained retrospectively from patient records.

A chart review was performed using our electronic medical record system to identify all patients undergoing primary ACL reconstruction between January 2011 and December 2013. For the purpose of this study, only patients with isolated ACL tears and patients with concomitant tears of the lateral meniscus were included for further analysis. Patients were excluded from the present study if they fulfilled one of the following criteria: concomitant insufficiency of the posterior cruciate ligament, concomitant grade 2 or 3 injury of the medial/lateral collateral ligament, concomitant tear of the medial meniscus, and a history of previous surgery at the index knee. Patient selection was performed after reviewing the preoperative clinical notes and the operation reports, which included documentation of the findings of the knee examination at the time of surgery with the patient under anesthesia and the findings of the diagnostic arthroscopy prior to ligament reconstruction. Since increased time from injury to surgery may contribute to subsequent meniscal tears, we additionally excluded patients who underwent surgery more than six months after the injury.

For medicolegal reasons, standardized photographic documentation of every diagnostic arthroscopy and of crucial steps of each arthroscopic procedure is mandatory at our institution, and all photographs are archived in a picture archiving and communication system (PACS). Therefore, digitalized arthroscopic photographs from the index procedure were available for all patients, which were reviewed by a single observer with extensive experience in arthroscopic knee surgery. Based on the arthroscopic appearance of the lateral meniscus, patients were assorted to one of three groups: 'no tear,' 'minor tear,' and 'major tear.' Tear patterns defined as minor were incomplete longitudinal tears or complete stable longitudinal tears not extending further than $1 \mathrm{~cm}$ in front of the popliteus tendon and radial or flap tears involving less than $75 \%$ of the meniscal width [18-20,23]. Tear patterns defined as major included root tears (defined as avulsion of the meniscus root or complete radial tears within $1 \mathrm{~cm}$ from the bony insertion of the lateral meniscus), complete radial tears with transection of the meniscus ('radial split tears'), and unstable longitudinal tears including bucket-handle tears (Figure 1) [21-24].

\section{Data collection}

The preoperative clinical notes of all patients were reviewed to collect demographic and historical data. The 


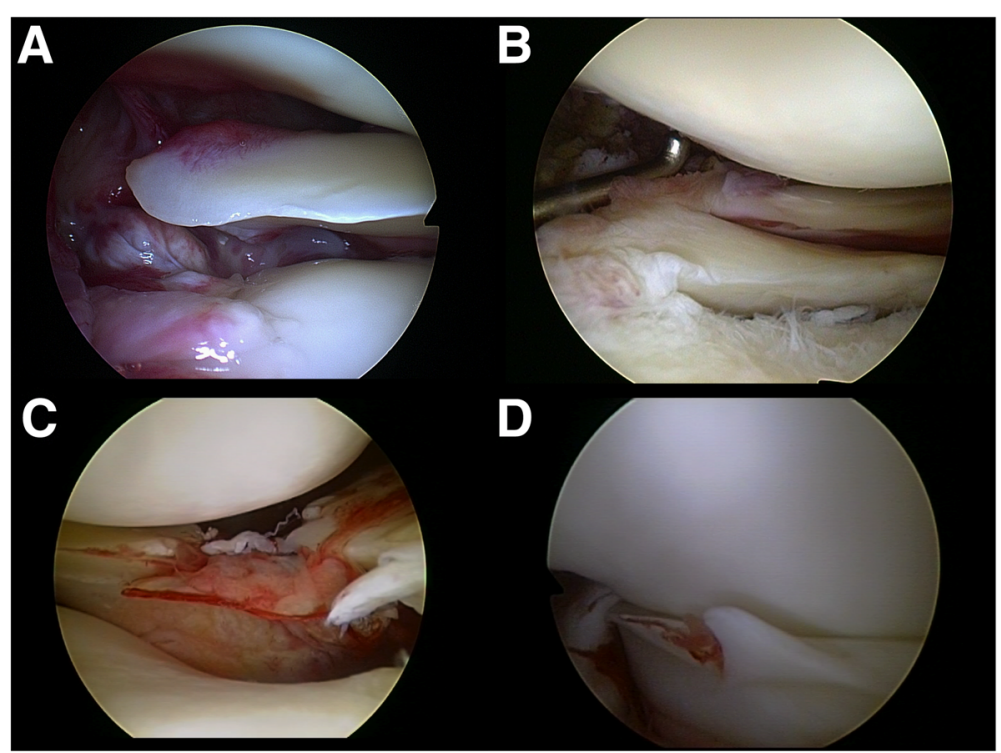

Figure 1 Lateral meniscus tears defined as major tears. Root tears (defined as avulsion of the meniscus root (A) or complete radial/oblique radial tears within one centimeter from the bony insertion of the lateral meniscus (B)); radial split tears $\mathbf{( C )}$ and unstable longitudinal tears including bucket-handle tears (D).

following variables were considered for the present study: gender, age at surgery, height, weight, body mass index (BMI), type of injury, and mechanism of injury. Patient age was further analyzed by dividing the cohort into two age groups: $<30$ years and $>30$ years. For BMI analysis, patients were divided into three groups based on the classification of the World Health Organization [25]: $<24.9 \mathrm{~kg} / \mathrm{m}^{2}$ (normal), $25-29.9 \mathrm{~kg} / \mathrm{m}^{2}$ (overweight), and $>30 \mathrm{~kg} / \mathrm{m}^{2}$ (obese). The type of injury was defined as the circumstance in which the injury occurred and was classified as high-impact sports-related, low-impact sports-related, and not sports-related injuries. The mechanism of injury was classified as non-contact mechanism or contact mechanism according to the definition of the Hunt Valley II Meeting in 2005 [26]. A non-contact mechanism was assumed if the forces applied to the knee joint resulted from the patients' own movements and did not involve contact with another person or object. A contact mechanism was assumed if an external force was directly applied to the knee joint or if an external force was applied to the patient but not directly to the injured knee.

\section{Statistical analysis}

Statistical analysis was performed using SPSS software version 21.0 (IBM-SPSS, New York, USA). The level of significance was set at $P<.05$. Continuous variables were calculated as mean \pm standard deviation and $95 \%$ confidence interval (CI). Categorical variables were reported as count and percentages.
Univariate analysis was performed by comparing the three study groups with regard to gender, age, age groups ( $<30$ years and $>30$ years), height, weight, BMI, BMI groups $(<24.9,25-29.9$, and $>30)$, type of injury (high-impact sports, low-impact sports, and not sports related), and mechanism of injury (non-contact and contact). Normal distribution of continuous variables was evaluated with the Kolmogorov-Smirnov test. Normally distributed continuous variables were compared using one-way analysis of variance (ANOVA) and the post hoc Tukey's honest significant difference test. Non-normal distributed continuous variables and categorical variables were compared using the Kruskal-Wallis test and chisquared test. Post hoc analyses were performed by multiple comparisons using the Mann-Whitney $U$ test or Fisher's exact test. For post hoc comparisons, the level of significance was corrected with a Bonferroni adjustment. Multivariate logistic regression was carried out to identify independent risk factors for minor and major tears. All variables were initially included in the multivariate models, and elimination of non-significant factors was performed using a stepwise backward elimination approach. Level of significance, odds ratios (OR), and 95\% CIs were calculated for each variable.

\section{Results}

A total of 268 patients underwent primary ACL reconstruction during the study period. Of these, 215 patients met the inclusion and exclusion criteria and were included in the present study. Thirty-six percent of the 
included patients were females and $64 \%$ were males. Mean age was $27.8 \pm 10$ years, mean height was $174.8 \pm$ $9.1 \mathrm{~cm}$, mean weight was $75.4 \pm 15.2 \mathrm{~kg}$, and mean BMI was $24.6 \pm 4.7 \mathrm{~kg} / \mathrm{m}^{2}$. Sixty-seven percent of the patients were aged $<30$ years and the BMI was normal in $65 \%$. Most patients (67\%) injured their ACL during highimpact sports and a non-contact mechanism was found in $79 \%$.

Of the 215 included patients, 120 (56\%) patients had isolated ACL tears, 58 (27\%) had an associated minor lateral meniscus tear, and $37(17 \%)$ had an associated major lateral meniscus tear. The detailed distribution of meniscus tear patterns is shown in Table 1. Patient characteristics of each group and the results of the univariate group comparison are presented in Table 2. Statistically significant differences between the 'no tear' and 'minor tear' groups were found for the mechanism of injury, with a higher proportion of contact injuries in the minor tear group $(p=0.006)$. Compared to patients with no tear, a significantly higher proportion of male patients $(p<0.001)$, patients $<30$ years $(p=0.015)$, and contact injuries $(p<0.001)$ were found in patients with major tears. In addition, contact injuries were significantly more common in patients with major tears as compared to patients with minor tears $(p=0.009)$. The results of the multivariate logistic regression analysis are shown in Table 3. The sole independent risk factor for a minor tear was a contact mechanism with an OR of 4.28 (95\% CI, 1.74-10.56). Independent risk factors for major tears were male gender (OR, 7.38; 95\% CI, 1.97-27.61), age $<30$ years (OR, 5.85; 95\% CI, 1.71-19.94), and a contact mechanism (OR, 18.49; 95\% CI, 5.96-57.37) (Figure 2).

\section{Discussion}

The purpose of this study was to identify risk factors for different tear patterns of the lateral meniscus in ACLinjured subjects who underwent surgery within 6 months after injury. Identified risk factors for major meniscal tears were male gender with an OR of 7.38 and age

\section{Table 1 Distribution of meniscus tear patterns}

\begin{tabular}{ll}
\hline Group & Number (\%) \\
\hline No tear & $120(56)$ \\
Minor tear & $58(27)$ \\
Incomplete/complete stable longitudinal tear & $45(21)$ \\
extending $<1 \mathrm{~cm}$ in front of the popliteus tendon & \\
Radial or flap tear involving $<75 \%$ of the meniscal & $13(6)$ \\
width & $37(17)$ \\
Major tear & $22(10)$ \\
Root tear & $8(4)$ \\
Radial split tear & $7(3)$ \\
Unstable longitudinal/bucket-handle tear &
\end{tabular}

Percentage values were calculated for the total study population. of $<30$ years with an OR of 5.85 . The strongest predictor for a major meniscal tear, however, was a contact injury mechanism with an OR of 18.49. The sole risk factor for a minor meniscal tear was a contact injury mechanism with an OR of 4.28.

Several other studies have evaluated risk factors for meniscus tears in ACL injuries before $[27,28,25,29,30$, 4,31-33,16,34-39,6,40,17]. Most of these studies, however, focused on the association between the timing of surgery and meniscal tears. It has been clearly demonstrated that the incidence of medial meniscus tears increases with delayed surgery whereas the incidence of lateral meniscus tears is independent of the time interval from injury to ACL reconstruction $[27,33,16,32,34,31,35,36,38,6,40,17]$. This finding implies that lateral meniscus tears typically emerge during the initial injury and other factors than surgical delay must be responsible for lateral meniscus tears in ACL-injured subjects. However, only few studies have analyzed the association between different demographic and historical factors and meniscal tears $[36,25,39]$. A recent comprehensive study examined the predictors of meniscal tears in 541 patients undergoing ACL reconstruction [25]. The analyzed predictors were similar to our study and included age, sex, BMI, mechanism of injury, type of injury, interval from injury to surgery, and instability episodes. The authors found that male sex predicted more lateral and more medial meniscus tears, sportsrelated injuries predicted fewer medial meniscal tears, and more instability episodes predicted more medial meniscus tears [25]. In a similar study, the association between meniscal injuries accompanying ACL tears and the mechanism of injury, time from injury, activity level after the initial trauma, re-injury after the initial trauma, and BMI was analyzed in 293 patients [39]. The authors found increasing time from injury, active daily life, and re-injury to be risk factors for meniscal injuries [39]. A limitation of both studies is that meniscus tears were considered a binary finding (meniscus tear vs. no meniscus tear) and no differentiation was made between different patterns of meniscus tears. However, the pattern of meniscus tears observed in ACL-injured subjects varies greatly and a differentiated perspective seems to be necessary because of their potential prognostic value $[41-43,14,5]$. Our study is novel in analyzing the association of different tear patterns of the lateral meniscus and patient specific risk factors. Meniscus tear patterns regarded as major within this study were root tears, radial split tears, and unstable longitudinal tears including bucket-handle tears. These tear patterns have shown to dramatically alter the loading profile of the knee joint in biomechanical studies and are thought to promote the onset and rapid progression of OA $[22,21,23,24,44]$. Repair of major meniscal tears at the time of ACL reconstruction should therefore be preferred over meniscectomy, since meniscus repair is associated 
Table 2 Univariate analysis ${ }^{\mathrm{a}}$

\begin{tabular}{|c|c|c|c|c|}
\hline \multirow[t]{2}{*}{ Variable } & \multicolumn{4}{|l|}{ Group } \\
\hline & 'No tear' & 'Minor tear' & 'Major tear' & $P$ value \\
\hline Gender & & & & $0.002^{b}$ \\
\hline Female & $51(43 \%)$ & $23(40 \%)$ & $4(11 \%)$ & \\
\hline Male & $69(58 \%)$ & $35(60 \%)$ & $33(89 \%)$ & \\
\hline Age (years) & $28.7 \pm 10.1$ & $27.6 \pm 10.0$ & $25.1 \pm 9.3$ & 0.086 \\
\hline \multicolumn{5}{|l|}{ Age groups (years) } \\
\hline$<30$ & 71 (59\%) & $42(72 \%)$ & $30(81 \%)$ & $0.026^{c}$ \\
\hline$>30$ & $49(41 \%)$ & $16(28 \%)$ & $7(19 \%)$ & \\
\hline Height (cm) & $173.7 \pm 9.2(172.1-175.4)$ & $175.2 \pm 8.7(172.9-177.4)$ & $177.8 \pm 8.8(174.9-180.7)$ & 0.052 \\
\hline Weight (kg) & $74.4 \pm 15.4(71.6-77.2)$ & $74.6 \pm 13.6(71.1-78.2)$ & $79.8 \pm 16.5(74.3-85.3)$ & 0.233 \\
\hline BMI $\left(\mathrm{kg} / \mathrm{m}^{2}\right)$ & $24.6 \pm 4.7(23.8-25.5)$ & $24.4 \pm 5.0(23.1-25.7)$ & $25.1 \pm 4.0(23.8-26.4)$ & 0.480 \\
\hline BMI groups $\left(\mathrm{kg} / \mathrm{m}^{2}\right)$ & & & & 0.590 \\
\hline$<24.9$ & $76(63 \%)$ & $42(72 \%)$ & $21(57 \%)$ & \\
\hline $25-29.9$ & $34(28 \%)$ & $13(22 \%)$ & $13(35 \%)$ & \\
\hline$>30$ & $10(8 \%)$ & $3(5 \%)$ & $3(8 \%)$ & \\
\hline Type of injury & & & & 0.728 \\
\hline High-impact sports & $81(68 \%)$ & $36(62 \%)$ & $28(76 \%)$ & \\
\hline Low-impact sports & $12(10 \%)$ & $6(10 \%)$ & $3(8 \%)$ & \\
\hline Not sports related & $27(23 \%)$ & $16(28 \%)$ & $6(16 \%)$ & \\
\hline Mechanism of injury & & & & $<0.001^{d}$ \\
\hline Non-contact & 109 (91\%) & $43(74 \%)$ & $17(46 \%)$ & \\
\hline Contact & $11(9 \%)$ & 15 (26\%) & 20 (54\%) & \\
\hline
\end{tabular}

${ }^{a}$ Continuous variables are shown as mean \pm standard deviation (95\% confidence interval), categorical variables are shown as number of patients and percentages per group.

${ }^{\mathrm{b}}$ Post hoc analyses revealed a significant difference between 'no tear' and 'major tear' $(P<0.001)$ and between 'minor tear' and 'major tear' $(P=0.002)$.

'Post hoc analysis revealed a significant difference between 'no tear' and 'major tear' $(P=0.015)$.

'Post hoc analyses revealed a significant difference between 'no tear' and 'minor tear' $(P=0.006)$, between 'no tear' and 'major tear' $(P<0.001)$, and between 'minor tear' and 'major tear' $(P=0.009)$.

with less cartilage degeneration and better clinical results $[12,45,7,46]$. All patients within this study with major meniscal tears underwent meniscal repair. In a recent systematic review, the treatment of meniscus tears during ACL reconstruction over the last 10 years was determined [1]. Unfortunately, the authors found that meniscectomy was the most common method of treatment. Lateral meniscus tears were treated by meniscectomy in $71 \%$, by repair in $14 \%$, and left in situ in $14 \%$. Interestingly, performing surgery within 6 weeks was predictive of more lateral meniscal repairs [1]. In addition, another study found higher meniscus healing rates in patients who underwent acute meniscus repair in conjunction with ACL reconstruction compared to delayed meniscus repair [47]. These findings underline the importance of early identification of patients with major meniscal tears if repair is attempted. The findings of the present study imply that male patients, patients under the age of 30, and particularly patients who sustained a contact injury are at high risk for an associated major lateral meniscus tear. We therefore recommend early referral of those patients to magnetic resonance imaging (MRI) and/or arthroscopy in order to allow meniscus repair in a timely manner.

A better understanding about factors associated with different patterns of lateral meniscus tears in ACLinjured subjects may also improve the diagnostic accuracy of MRI. Several studies have reported that the sensitivity and negative predictive value of MRI for meniscal tears decreases in the presence of ACL tears, particularly for the lateral meniscus [48-50]. A high index of suspicion is therefore necessary for adequate diagnosis. Based on the findings of the present study, special attention for lateral meniscus tears has to be given in males, patients $<30$ years, and patients presenting after a contact injury.

The present study found a contact injury mechanism to be the strongest risk factor for an associated major lateral meniscus tear. In contrast, other authors did not find that contact injuries predicted meniscus tears $[25,39]$. However, these studies did not differentiate between tear patterns and included both acute and chronic ACL injuries, which might be one explanation for the different results. In our opinion, the high risk for associated 
Table 3 Multivariate logistic regression ${ }^{a}$

\begin{tabular}{|c|c|c|c|c|c|c|}
\hline \multirow[t]{3}{*}{ Variable } & \multicolumn{6}{|l|}{ Group } \\
\hline & \multicolumn{3}{|c|}{ 'Minor tear' } & \multicolumn{3}{|c|}{ ‘Major tear' } \\
\hline & $\mathrm{OR}$ & $95 \% \mathrm{Cl}$ & $P$ value & $\overline{O R}$ & $95 \% \mathrm{Cl}$ & $P$ value \\
\hline \multicolumn{7}{|l|}{ Gender } \\
\hline Female & Referent & & & Referent & & \\
\hline Male & 1.37 & $0.51-3.67$ & 0.530 & 7.38 & $1.97-27.61$ & $0.003^{b}$ \\
\hline Age (years) & 0.94 & $0.89-1.00$ & 0.057 & 0.96 & $0.87-1.06$ & 0.405 \\
\hline \multicolumn{7}{|l|}{ Age groups (years) } \\
\hline$<30$ & 1.812 & $0.92-3.58$ & 0.098 & 5.85 & $1.71-19.94$ & $0.005^{b}$ \\
\hline$>30$ & Referent & & & Referent & & \\
\hline Height (cm) & 1.00 & $0.96-1.03$ & 0.701 & 1.18 & $0.85-1.66$ & 0.327 \\
\hline Weight (kg) & 1.08 & $0.86-1.35$ & 0.534 & 0.98 & $0.91-1.05$ & 0.483 \\
\hline BMI $\left(\mathrm{kg} / \mathrm{m}^{2}\right)$ & 0.95 & $0.83-1.08$ & 0.438 & 1.02 & $0.91-1.15$ & 0.735 \\
\hline \multicolumn{7}{|l|}{ BMl groups $\left(\mathrm{kg} / \mathrm{m}^{2}\right)$} \\
\hline$<24.9$ & Referent & & & Referent & & \\
\hline $25-29.9$ & 0.32 & $0.07-1.42$ & 0.134 & 1.49 & $0.03-4.38$ & 0.837 \\
\hline$>30$ & 0.46 & $0.09-2.25$ & 0.336 & 1.41 & $0.07-2.83$ & 0.824 \\
\hline \multicolumn{7}{|l|}{ Type of injury } \\
\hline High-impact sports & 1.49 & $0.63-3.48$ & 0.362 & 0.61 & $0.16-2.31$ & 0.466 \\
\hline Low-impact sports & 1.12 & $0.30-4.18$ & 0.865 & 0.57 & $0.08-4.00$ & 0.572 \\
\hline Not sports related & Referent & & & Referent & & \\
\hline \multicolumn{7}{|l|}{ Mechanism of injury } \\
\hline Non-contact & Referent & & & Referent & & \\
\hline Contact & 4.28 & $1.74-10.56$ & $0.002^{b}$ & 18.49 & $5.96-57.37$ & $<0.001^{b}$ \\
\hline
\end{tabular}

'The reference group was 'no tear.'

${ }^{b}$ Statistically significant.

major lateral meniscus tears during contact injuries may be explained by higher forces applied to the knee joint compared to non-contact injuries. This assumption is supported by the observed higher incidence and severity of associated chondral lesions in contact ACL injuries [39]. With regard to the type of injury, we did not observe differences between high-impact sports-related, low-impact sports-related, and not sports-related injuries. This finding is in accordance with the results of other studies [25,31]. Other authors compared different injury patterns with regard to specific sports disciplines and reported that compared with soccer, skiing had an increased odds of isolated ACL injuries and other ligament injuries but decreased odds of meniscus and cartilage injuries, American football

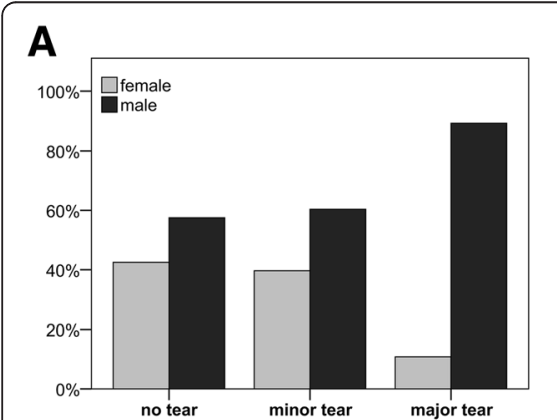

B

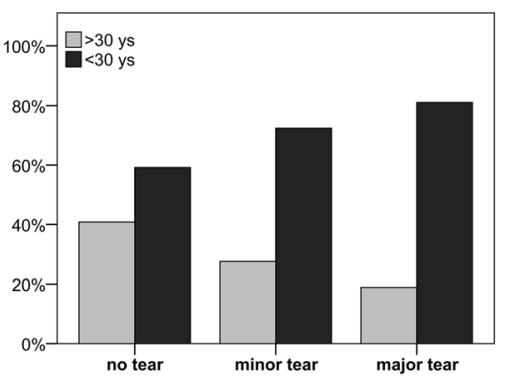

C

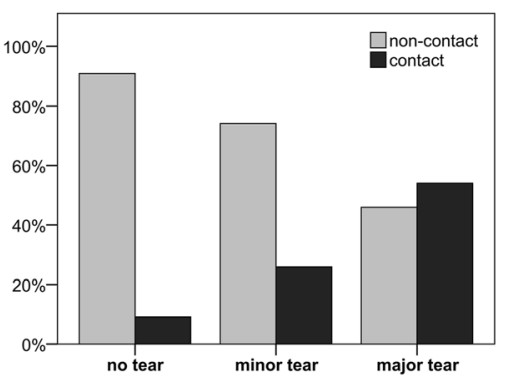

Figure 2 Significant results. Distribution of gender (A), age groups (B), and injury mechanism (C) within each group. The sole independent risk factor for a minor tear was a contact mechanism. Independent risk factors for major tears were male gender, age <30 years, and a contact mechanism. 
had a higher likelihood of having multiligament injuries compared with soccer, and basketball had a higher likelihood of having cartilage and lateral meniscus injuries than soccer [51]. Given the fact that a contact mechanism was the strongest risk factor for a major meniscal tear within the present study, we believe that the mechanism of injury might be more important than the type of injury.

Similar to our study, other studies have also found an association between male sex and an increased prevalence of concomitant meniscus tears $[27,28,4,30,25]$. However, these studies did not differentiate between different meniscus tear patterns. In the present study, male sex was only predictive for major meniscal tears whereas gender distribution was similar among patients with no tear or a minor tear. This association may be explained by a lesser degree of ACL resilience in females, leading to ACL rupture at smaller forces and thus less associated meniscal damage [28]. A higher failure load of the ACL may also explain the observed higher risk for associated major lateral meniscus tears in younger patients.

This study has several limitations that have to be considered when interpreting our results. First, this was a retrospective study and therefore the validity of our findings is limited. Second, the sample size of 215 patients is relatively low for an epidemiologic study. Third, only patients electing ACL reconstruction were evaluated and therefore the results may not allow generalization to all patients presenting with an ACL tear. Fourth, the injury mechanism was self-reported by the patients which might have introduced an information bias. Fifth, other factors not examined in this study may exist that predict the tear pattern, such as differences in knee morphology or material properties of the meniscus.

\section{Conclusions}

Among patients with a tear of the ACL, male sex, age $<30$ years, and a contact injury mechanism are independent risk factors for concomitant major meniscal tears. Patients with a contact injury mechanism have an approximately 18-fold increased risk for a major lateral meniscus tear compared to patients with a non-contact injury. Special attention for this injury pattern is therefore necessary in those patients and early referral to magnetic resonance imaging and/or arthroscopy is recommended in order to allow meniscus repair in a timely manner.

\section{Competing interests}

The authors declare that they have no competing interests.

\section{Authors' contributions}

MJF and SB designed the study, collected data, performed the statistical analysis, and wrote the manuscript. MJF drafted the manuscript. GB, GMS, and DDA helped to design the study, assisted with statistical analysis and data interpretation, and critically reviewed the manuscript. NPS and PN conceived of the study, helped with data interpretation and critically reviewed the manuscript. All authors read and approved the final manuscript.

\section{Acknowledgements}

The article processing charge was funded by the German Research Foundation (DFG) and the Albert Ludwigs University Freiburg in the funding program Open Access Publishing.

Received: 27 January 2015 Accepted: 4 March 2015

Published online: 18 March 2015

\section{References}

1. Noyes FR, Barber-Westin SD. Treatment of meniscus tears during anterior cruciate ligament reconstruction. Arthroscopy. 2012;28:123-30. doi:10.1016/j. arthro.2011.08.292.

2. Wyatt RW, Inacio MC, Liddle KD, Maletis GB. Factors associated with meniscus repair in patients undergoing anterior cruciate ligament reconstruction. Am J Sports Med. 2013;41:2766-71. doi:10.1177/ 0363546513503287.

3. Smith 3rd JP, Barrett GR. Medial and lateral meniscal tear patterns in anterior cruciate ligament-deficient knees. A prospective analysis of 575 tears. Am J Sports Med. 2001;29:415-9.

4. Slauterbeck JR, Kousa P, Clifton BC, Naud S, Tourville TW, Johnson RJ, et al. Geographic mapping of meniscus and cartilage lesions associated with anterior cruciate ligament injuries. J Bone Joint Surg Am. 2009;91:2094-103. doi:10.2106/JBJS.H.00888.

5. Ghodadra N, Mall NA, Karas V, Grumet RC, Kirk S, McNickle AG, et al. Articular and meniscal pathology associated with primary anterior cruciate ligament reconstruction. J Knee Surg. 2013;26:185-93. doi:10.1055/s-00321327450.

6. Michalitsis S, Vlychou M, Malizos KN, Thriskos P, Hantes ME. Meniscal and articular cartilage lesions in the anterior cruciate ligament-deficient knee: correlation between time from injury and knee scores. Knee Surg Sports Traumatol Arthrosc. 2013. doi:10.1007/s00167-013-2497-9.

7. Magnussen RA, Mansour AA, Carey JL, Spindler KP. Meniscus status at anterior cruciate ligament reconstruction associated with radiographic signs of osteoarthritis at 5- to 10-year follow-up: a systematic review. J Knee Surg. 2009;22:347-57.

8. Shelbourne KD, Gray T. Results of anterior cruciate ligament reconstruction based on meniscus and articular cartilage status at the time of surgery. Five- to fifteen-year evaluations. Am J Sports Med. 2000;28:446-52.

9. Oiestad BE, Engebretsen L, Storheim K, Risberg MA. Knee osteoarthritis after anterior cruciate ligament injury: a systematic review. Am J Sports Med. 2009;37:1434-43. doi:10.1177/0363546509338827.

10. Cohen M, Amaro JT, Ejnisman B, Carvalho RT, Nakano KK, Peccin MS, et al. Anterior cruciate ligament reconstruction after 10 to 15 years: association between meniscectomy and osteoarthrosis. Arthroscopy. 2007;23:629-34. doi:10.1016/j.arthro.2007.03.094.

11. Cox CL, Huston LJ, Dunn WR, Reinke EK, Nwosu SK, Parker RD, et al. Are articular cartilage lesions and meniscus tears predictive of IKDC, KOOS, and Marx activity level outcomes after anterior cruciate ligament reconstruction? A 6-year multicenter cohort study. Am J Sports Med. 2014;42:1058-67. doi:10.1177/0363546514525910.

12. Shelbourne KD, Dersam MD. Comparison of partial meniscectomy versus meniscus repair for bucket-handle lateral meniscus tears in anterior cruciate ligament reconstructed knees. Arthroscopy. 2004;20:581-5. Doi: 10.1016/j. arthro.2004.03.009.

13. Toman CV, Dunn WR, Spindler KP, Amendola A, Andrish JT, Bergfeld JA, et al. Success of meniscal repair at anterior cruciate ligament reconstruction. Am J Sports Med. 2009;37:1111-5. doi:10.1177/0363546509337010.

14. Cipolla M, Scala A, Gianni E, Puddu G. Different patterns of meniscal tears in acute anterior cruciate ligament $(\mathrm{ACL})$ ruptures and in chronic $\mathrm{ACL}$-deficient knees. Classification, staging and timing of treatment. Knee Surg Sports Traumatol Arthrosc. 1995;3:130-4.

15. Nikolic DK. Lateral meniscal tears and their evolution in acute injuries of the anterior cruciate ligament of the knee. Arthroscopic analysis. Knee Surg Sports Traumatol Arthrosc. 1998;6:26-30.

16. Keene GC, Bickerstaff D, Rae PJ, Paterson RS. The natural history of meniscal tears in anterior cruciate ligament insufficiency. Am J Sports Med. 1993:21:672-9.

17. Fok AW, Yau WP. Delay in ACL reconstruction is associated with more severe and painful meniscal and chondral injuries. Knee Surg Sports Traumatol Arthrosc. 2013;21:928-33. doi:10.1007/s00167-012-2027-1. 
18. Pujol N, Beaufils P. Healing results of meniscal tears left in situ during anterior cruciate ligament reconstruction: a review of clinical studies. Knee Surg Sports Traumatol Arthrosc. 2009;17:396-401. doi:10.1007/s00167-0080711-y.

19. Fitzgibbons RE, Shelbourne KD. "Aggressive" nontreatment of lateral meniscal tears seen during anterior cruciate ligament reconstruction. Am J Sports Med. 1995;23:156-9.

20. Shelbourne KD, Heinrich J. The long-term evaluation of lateral meniscus tears left in situ at the time of anterior cruciate ligament reconstruction. Arthroscopy. 2004:20:346-51. doi:10.1016/j.arthro.2004.01.029.

21. Laprade CM, Jansson KS, Dornan G, Smith SD, Wijdicks CA, Laprade RF. Altered tibiofemoral contact mechanics due to lateral meniscus posterior horn root avulsions and radial tears can be restored with in situ pull-out suture repairs. J Bone Joint Surg Am. 2014;96:471-9. doi:10.2106/JBJS.L.01252.

22. Forkel P, Herbort M, Sprenker F, Metzlaff S, Raschke M, Petersen W. The biomechanical effect of a lateral meniscus posterior root tear with and without damage to the meniscofemoral ligament: efficacy of different repair techniques. Arthroscopy. 2014;30:833-40. doi:10.1016/j.arthro.2014.02.040.

23. Ode GE, Van Thiel GS, McArthur SA, Dishkin-Paset J, Leurgans SE, Shewman $E F$, et al. Effects of serial sectioning and repair of radial tears in the lateral meniscus. Am J Sports Med. 2012:40:1863-70. doi:10.1177/ 0363546512453291.

24. Schillhammer CK, Werner FW, Scuderi MG, Cannizzaro JP. Repair of lateral meniscus posterior horn detachment lesions: a biomechanical evaluation. Am J Sports Med. 2012;40:2604-9. doi:10.1177/0363546512458574.

25. Kluczynski MA, Marzo JM, Bisson LJ. Factors associated with meniscal tears and chondral lesions in patients undergoing anterior cruciate ligament reconstruction: a prospective study. Am J Sports Med. 2013;41:2759-65. doi:10.1177/0363546513503448.

26. Hewett TE, Shultz SJ, Griffin LY. Understanding and preventing noncontact ACL injuries. Champaign, IL: Human Kinetics; 2007.

27. Chhadia AM, Inacio MC, Maletis GB, Csintalan RP, Davis BR, Funahashi TT. Are meniscus and cartilage injuries related to time to anterior cruciate ligament reconstruction? Am J Sports Med. 2011;39:1894-9. doi:10.1177/ 0363546511410380.

28. Piasecki DP, Spindler KP, Warren TA, Andrish JT, Parker RD. Intraarticular injuries associated with anterior cruciate ligament tear: findings at ligament reconstruction in high school and recreational athletes. An analysis of sex-based differences. Am J Sports Med. 2003;31:601-5.

29. Bowers AL, Spindler KP, MCCarty EC, Arrigain S. Height, weight, and BMI predict intra-articular injuries observed during $A C L$ reconstruction: evaluation of 456 cases from a prospective ACL database. Clin J Sport Med. 2005;15:9-13.

30. O'Connor DP, Laughlin MS, Woods GW. Factors related to additional knee injuries after anterior cruciate ligament injury. Arthroscopy. 2005;21:431-8. doi:10.1016/j.arthro.2004.12.004

31. Tandogan RN, Taser O, Kayaalp A, Taskiran E, Pinar H, Alparslan B, et al. Analysis of meniscal and chondral lesions accompanying anterior cruciate ligament tears: relationship with age, time from injury, and level of sport. Knee Surg Sports Traumatol Arthrosc. 2004;12:262-70. doi:10.1007/s00167003-0398-z.

32. Murrell GA, Maddali S, Horovitz L, Oakley SP, Warren RF. The effects of time course after anterior cruciate ligament injury in correlation with meniscal and cartilage loss. Am J Sports Med. 2001;29:9-14.

33. Millett PJ, Willis AA, Warren RF. Associated injuries in pediatric and adolescent anterior cruciate ligament tears: does a delay in treatment increase the risk of meniscal tear? Arthroscopy. 2002;18:955-9.

34. Church S, Keating JF. Reconstruction of the anterior cruciate ligament: timing of surgery and the incidence of meniscal tears and degenerative change. J Bone Joint Surg (Br). 2005;87:1639-42. doi:10.1302/0301620X.87B12.16916.

35. Yuksel HY, Erkan S, Uzun M. The evaluation of intraarticular lesions accompanying ACL ruptures in military personnel who elected not to restrict their daily activities: the effect of age and time from injury. Knee Surg Sports Traumatol Arthrosc. 2006;14:1139-47. doi:10.1007/s00167-0060170-2.

36. Dumont GD, Hogue GD, Padalecki JR, Okoro N, Wilson PL. Meniscal and chondral injuries associated with pediatric anterior cruciate ligament tears: relationship of treatment time and patient-specific factors. Am J Sports Med. 2012:40:2128-33. doi:10.1177/0363546512449994.
37. Granan LP, Bahr R, Lie SA, Engebretsen L. Timing of anterior cruciate ligament reconstructive surgery and risk of cartilage lesions and meniscal tears: a cohort study based on the Norwegian National Knee Ligament Registry. Am J Sports Med. 2009;37:955-61. doi:10.1177/0363546508330136.

38. Papastergiou SG, Koukoulias NE, Mikalef P, Ziogas E, Voulgaropoulos H. Meniscal tears in the ACL-deficient knee: correlation between meniscal tears and the timing of $\mathrm{ACL}$ reconstruction. Knee Surg Sports Traumatol Arthrosc. 2007;15:1438-44. doi:10.1007/s00167-007-0414-9.

39. Chen G, Tang X, Li Q, Zheng G, Yang T, Li J. The evaluation of patient-specific factors associated with meniscal and chondral injuries accompanying ACL rupture in young adult patients. Knee Surg Sports Traumatol Arthrosc. 2013. doi:10.1007/s00167-013-2718-2.

40. Magnussen RA, Pedroza AD, Donaldson CT, Flanigan DC, Kaeding CC. Time from ACL injury to reconstruction and the prevalence of additional intraarticular pathology: is patient age an important factor? Knee Surg Sports Traumatol Arthrosc. 2013;21:2029-34. doi:10.1007/s00167-013-2380-8.

41. Beldame J, Wajisz A, Lespagnol F, Hulet C, Seil R. Lateral meniscus lesions on unstable knee. Orthop Traumatol Surg Res. 2009;95:S65-9. doi:10.1016/j. otsr.2009.09.007.

42. Binfield PM, Maffulli N, King JB. Patterns of meniscal tears associated with anterior cruciate ligament lesions in athletes. Injury. 1993;24:557-61.

43. Cerabona F, Sherman MF, Bonamo JR, Sklar J. Patterns of meniscal injury with acute anterior cruciate ligament tears. Am J Sports Med. 1988;16:603-9.

44. Bedi A, Kelly N, Baad M, Fox AJ, Ma Y, Warren RF, et al. Dynamic contact mechanics of radial tears of the lateral meniscus: implications for treatment. Arthroscopy. 2012;28:372-81. doi:10.1016/j.arthro.2011.08.287.

45. Barenius B, Ponzer S, Shalabi A, Bujak R, Norlen L, Eriksson K. Increased risk of osteoarthritis after anterior cruciate ligament reconstruction: a 14-year follow-up study of a randomized controlled trial. Am J Sports Med. 2014;42:1049-57. doi:10.1177/0363546514526139.

46. Wu WH, Hackett T, Richmond JC. Effects of meniscal and articular surface status on knee stability, function, and symptoms after anterior cruciate ligament reconstruction: a long-term prospective study. Am J Sports Med. 2002;30:845-50.

47. Tenuta JJ, Arciero RA. Arthroscopic evaluation of meniscal repairs. Factors that effect healing. Am J Sports Med. 1994;22:797-802.

48. De Smet AA, Graf BK. Meniscal tears missed on MR imaging: relationship to meniscal tear patterns and anterior cruciate ligament tears. AJR Am J Roentgenol. 1994;162:905-11. doi:10.2214/ajr.162.4.8141016.

49. Jee WH, McCauley TR, Kim JM. Magnetic resonance diagnosis of meniscal tears in patients with acute anterior cruciate ligament tears. J Comput Assist Tomogr. 2004;28:402-6.

50. Laundre BJ, Collins MS, Bond JR, Dahm DL, Stuart MJ, Mandrekar JN. MRI accuracy for tears of the posterior horn of the lateral meniscus in patients with acute anterior cruciate ligament injury and the clinical relevance of missed tears. AJR Am J Roentgenol. 2009;193:515-23. doi:10.2214/ AJR.08.2146.

51. Granan LP, Inacio MC, Maletis GB, Funahashi TT, Engebretsen L. Sport-specific injury pattern recorded during anterior cruciate ligament reconstruction. Am J Sports Med. 2013;41:2814-8. doi:10.1177/0363546513501791.

\section{Submit your next manuscript to BioMed Central and take full advantage of:}

- Convenient online submission

- Thorough peer review

- No space constraints or color figure charges

- Immediate publication on acceptance

- Inclusion in PubMed, CAS, Scopus and Google Scholar

- Research which is freely available for redistribution 